\title{
LA NOVELA DE CABALLERO BONALD. FICCIÓN Y MEMORIA
}

\author{
Antonio Unzué Unzué \\ aunzueun@yahoo.es
}

\section{RESUMEN}

En el contexto del debate en torno a la renovación de la novela y la autobiografía, se analiza la obra narrativa de José Manuel Caballero Bonald, con especial atención al desafío planteado por las novelas de la memoria. Se interpretan así los sucesivos pactos de lectura de estas obras, marcando el tránsito de la escritura ficcional a la memorialística, en un marco de cuestionamiento genérico. Asimismo, se pondera la contribución de Caballero Bonald al debate en torno a los conceptos de ficción, autobiografía y memorialismo, como factor de renovación literaria.

PALABRAS Clave: Ficción, novela, memorias, autobiografía.

\section{RÉSUMÉ}

Dans le contexte du débat générique à propos du renouvellement du roman et de l'autobiographie, on analyse l'œuvre narrative de José Manuel Caballero Bonald, tout en mettant l'accent sur le défi suscité par les «romans de la mémoire». On interprète ainsi les successifs pactes de lecture, en soulignant le passage de l'écriture fictionnelle aux mémoires, dans un cadre de controverse générique. De même, on souligne la contribution de Caballero Bonald au débat générique à propos des notions de fiction, autobiographie et mémoires, ce qui déclanche un procès de renouvellement littéraire.

MotS-CLEF: Fiction, roman, mémoires, autobiographie. 
El análisis de la producción narrativa de Caballero Bonald, incluyendo en ella sus memorias, resulta interesante para el conocimiento de una faceta básica en un escritor de gran prestigio entre los de su generación. Constituye también un acercamiento a los cambios experimentados por la narrativa española a lo largo de la segunda mitad del siglo XX. Asimismo, permite valorar la importancia de lo biográfico como materia prima de la ficción, descubrir la fragilidad de las fronteras genéricas y apreciar la aportación del escritor jerezano en los límites borrosos entre la ficción y la escritura memorialística.

Este trabajo pretende elucidar el peso de lo autobiográfico y sus límites genéricos en las novelas del escritor jerezano, particularmente en las llamadas novelas de la memoria, examinándolas dentro del debate actual sobre el género autobiográfico y el concepto de ficción.

\section{UNA CONSTRUCCIÓN NARRATIVA DE BASE AUTOBIOGRÁFICA}

El análisis del pacto narrativo de la obra novelística de Caballero Bonald deviene una cuestión paradigmática en un contexto crítico caracterizado por el cuestionamiento de las fronteras genéricas y de los límites entre autobiografía y ficción. Toda la obra narrativa del escritor jerezano está construida a partir de elementos muy reconocibles de su experiencia personal. Ahora bien, la manipulación de estos rasgos y su integración en una propuesta literaria concreta derivan en resultados muy diversos.

Una lectura atenta de las novelas de Caballero Bonald permite identificar ciertos rasgos característicos del mundo propio de este escritor, de clara base autobiográfica, en todos los aspectos básicos de la sintaxis narrativa: los conflictos sociales o íntimos; los personajes, que reflejan la sociedad de la que son producto y las inquietudes del autor; el tiempo, en el que se incluyen los problemas principales de la España del siglo XX; y sobre todo, el espacio bajoandaluz, que aparece de forma recurrente en todas estas narraciones.

Por lo que respecta a los conflictos básicos de estas novelas, puede distinguirse entre aquellos relatos, como Dos días de setiembre (1962), Ágata ojo de gato (1974), Toda la noche oyeron pasar pájaros (1981) y En la casa del padre (1988), que atienden preferentemente a las cuestiones socioeconómicas del ámbito jerezano o sanluqueño, y los que inciden en la dinámica interior del protagonista, circunstancia dominante en Campo de Agramante (1992) y las novelas de la memoria, Tiempo de guerras perdidas (1995) y La costumbre de vivir (2001). Precisamente esta secuencia de construcción personal, de autodescubrimiento y afirmación, resulta una recurrencia presente, en diferente grado, en toda la obra narrativa del autor.

En cuanto a los personajes, existen también ciertas conexiones entre los miembros de la familia del protagonista de Tiempo de guerras perdidas y varios personajes de otras novelas. Así, la hipersensibilidad materna ante los ruidos, afección heredada por el hijo, es común en las memorias y en Campo de Agramante. También es idéntica la tendencia depresiva en los padres de ambos protagonistas. Por otro lado, la tía Carola de Tiempo de guerras perdidas, viuda de un militar y residente en Madrid, comparte con el personaje homónimo de En la casa del padre, además del nombre, igual prestancia física, al margen de la edad que pueda suponérseles a ambos personajes. La figura de tío 
Antonio Bonald, desaparecido en Madrid al comienzo de la guerra civil, reproduce la trayectoria de Juan Claudio Vallon, de En la casa del padre, cuyo destino final no llega a aclararse.

Otras figuras de esta primera parte de las memorias se asocian con personajes de las novelas anteriores. Así, por ejemplo, los marqueses de Negrón y de Patrón, vecinos del protagonista en la calle Caballeros y fervientes franquistas, hacen pensar en don Fermín Benijalea de Toda la noche oyeron pasar pájaros y en Alfonso María de En la casa del padre. En la etapa gaditana, el lector encuentra en las memorias una dama, propietaria de un enorme caserón, en el que organiza traslados periódicos que recuerdan a los que protagoniza doña Purificación Bárcena, la madre de don Sebastián, de En la casa del padre. Asimismo, en Tiempo de guerras perdidas comparece un tal Mojarrita, un buzo conocedor de los fondos marinos. Este personaje se encuentra ya en Toda la noche oyeron pasar pájaros como sobrino de Leonardo Fabeiro.

En La costumbre de vivir, la segunda entrega de las novelas de la memoria, destaca la figura del protagonista en pleno proceso de construcción personal. Muchos de los detalles que lo caracterizan remiten al personaje principal de Campo de Agramante. Así, la inquietud psicológica marca su conducta. Estos trastornos, vinculados a causas dispares como los traslados, las incertidumbres existenciales y los excesos alcohólicos, constituyen una constante del protagonista. Muchos de estos rasgos se reproducen en el personaje de Campo de Agramante, asediado por las anomalías sensoriales, el desequilibrio psicológico, el abuso del alcohol y el temor a la recaída.

Otros rasgos del protagonista de La costumbre de vivir, como su afición por la cultura árabe o la preocupación por el urbanismo, surgen de nuevo en el personaje principal de Campo de Agramante. Asimismo, la vinculación familiar de aquel con Cuba reaparece en la figura de tía Socorro de En la casa del padre, propietaria en Cuba de una plantación que ella y su marido, Alfonso María, intentan recuperar tras la revolución castrista. En definitiva, es notoria la conexión entre los personajes de las memorias, de clara inspiración autobiográfica, y los del resto de las novelas.

En cuanto al tiempo, pueden destacarse algunas constantes de base autobiográfica: la delimitación cronológica, que comprende de la Restauración a la posguerra, con especial énfasis en la guerra civil y sus consecuencias; o la conexión entre memoria y narración, lo que permite relacionar el narrador de las novelas de la memoria con otros narradores personales de novelas anteriores.

Pero tal vez ningún aspecto resulta tan determinante en la configuración de un mundo propio como la presencia constante del espacio bajoandaluz en todas estas novelas. La acción de la primera de ellas se sitúa en una población vitícola innominada, que el lector identifica fácilmente con Jerez. En la segunda, la acción se traslada al espacio marismeño de Doñana, pero convertido en un mundo mítico. En Toda la noche oyeron pasar pájaros, el autor ubica la acción en una ciudad portuaria sin identificar cercana a la Argónida de Ágata ojo de gato, lo que permite considerar que se trata de un trasunto de Sanlúcar de Barrameda. Con En la casa del padre, el autor vuelve al espacio de su primera novela, lugar que puede relacionarse con Jerez, si bien no llega a indicarse textualmente en la narración. Así, en estas novelas alternan el mundo urbano y el espacio natural, las ciudades portuarias y las poblaciones vitícolas, en definitiva, distintos rincones de una misma comarca. 
A partir de Campo de Agramante, el autor prefiere la ubicación de la historia en un espacio más claramente identificado. Así, son frecuentes los datos acerca del deambular del protagonista por Sanlúcar, lo que no impide la permanencia de una toponimia ficcional presente ya en relatos anteriores, particularmente Argónida, transposición literaria de Doñana, el espacio predilecto del autor. Por lo que respecta a las novelas de la memoria, el lector identifica en ellas numerosas conexiones con el mundo de los anteriores relatos: las casas, la naturaleza salvaje de Doñana, la fisonomía urbana de Jerez... Todo lo cual afianza la solidez de un espacio narrativo muy unido al ámbito personal del autor.

\section{El PACTO NARRATIVo EN LAS NOVELAS DE CABALleRo Bonald}

Atendiendo al concepto de pacto formulado por Philippe Lejeune (1994), pueden distinguirse dos grandes grupos: por un lado, las cuatro primeras novelas, que suscriben desde enfoques muy diversos el planteamiento novelístico; por otro, las novelas de la memoria, que sugieren una recepción ambigua. A este respecto, Campo de Agramante funciona como nexo entre ambas propuestas.

Dentro de la producción narrativa de Caballero Bonald, el primer bloque se atiene a un pacto indudablemente novelístico. Esto es así a pesar del evidente fundamento autobiográfico de muchos elementos narrativos y también a pesar de las notables diferencias de modelo perceptibles entre unos relatos y otros. Ahora bien, la constatación de que el autor se revela en su obra debe entenderse a la luz del compromiso concreto que plantea al lector en el texto.

Ya en Dos días de setiembre resulta evidente la manipulación del material autobiográfico. El propio autor lo reconoce, aceptando, no sólo en esta novela sino en las siguientes, la concurrencia de personajes con los que se siente en cierto modo identificado. Uno de ellos, Miguel Gamero, destaca por su espíritu crítico, que le lleva a rechazar las estructuras sociales de la ciudad, y por una notable incapacidad para articular una respuesta efectiva a la situación. La tendencia depresiva, la afición al alcohol y la sensación de desclasamiento son rasgos comunes con otros personajes del autor, particularmente el protagonista de las novelas de la memoria.

Ahora bien, desde el punto de vista formal, el narrador dominante en tercera persona se ajusta a una de las disposiciones más frecuentes en el discurso ficcional, esto es, la intervención de una voz externa al relato como elemento de transmisión de la historia. Esta voz en tercera persona se distingue sin problemas del autor, de modo que con ello queda descartado uno de los componentes básicos de la narración autobiográfica. No obstante, cabe recordar que numerosas intervenciones de esta voz narrativa constituyen rasgos de autor implícito. Sucede así, sobre todo, en las presentaciones irónicas o caricaturescas de algunos personajes, como don Gabriel. Se incorpora con ello, dentro del esquema novelístico, una evidente referencia personal. En cuanto al otro narrador, Miguel Gamero, que interviene a través de un discurso en forma de corriente de conciencia, ya se han señalado sus abundantes conexiones con la figura del autor.

Respecto a la cuestión de la ficcionalidad, conviene subrayar la constitución ficcional del relato, a pesar de las numerosas indicaciones personales. Los elementos autobiográficos señalados en Dos días de setiembre, que incluyen las valoraciones del na- 
rrador, la percepción del espacio o la psicología de algunos personajes, se integran dentro de un relato construido según el pacto novelístico. Por otra parte, el contexto literario y social influye en el momento de la redacción de esta primera novela de Caballero Bonald en la medida en que el autor contiene su tendencia natural al barroquismo expresivo, con la intención de construir una historia que, además de su efectividad estética, pueda dar testimonio de una realidad social concreta, la de su comarca natal. Esta utilidad de la obra literaria, por más que siempre en el autor tiene un carácter subsidiario, será después objeto de revisión en obras posteriores.

En efecto, con Ágata ojo de gato el autor da un giro notable a su orientación narrativa. Frente al testimonialismo, el tiempo reducido, el personaje colectivo y otros rasgos deudores del realismo social, en esta segunda novela el escritor deja fluir su imaginación más libremente, lo cual se percibe no sólo en la diversidad anecdótica de la trama, sino también en el barroquismo expresivo. Todo ello, por otro lado, resulta favorecido por el contexto. Frente al apogeo de la novela social a finales de los cincuenta y primeros sesenta, en la década de los setenta se asiste al triunfo del experimentalismo. Este marco literario, más próximo a las preferencias del autor, favorece un tipo de relato de recepción más exigente.

A pesar del cambio de tendencia estilística, se observa cómo en esta segunda novela se mantiene la presencia de elementos personales y se afianza un rasgo presente ya en la primera, la exigencia estética de la prosa. Todo ello, dentro de los cánones propios de la escritura novelística, como puede observarse en la presencia de un narrador extradiegético que alterna entre la presentación objetiva y el comentario, por más que la ironía de algunos pasajes permita reconocer la imagen del autor.

Los distintos elementos compositivos de esta historia se integran en un relato que adopta un cierto aire de fábula, combinando hábilmente relato mítico y narración histórica, en un experimento narrativo de gran exigencia estética que aspira a trazar una interpretación literaria de la realidad que le rodea. La ficción constituye, en efecto, además de una propuesta estrictamente artística, una reflexión sobre la realidad en su significado más amplio. Dentro de esa realidad, como es natural, son numerosos los referentes personales, pero la propuesta se ajusta con claridad a los parámetros genéricos.

La tercera novela, Toda la noche oyeron pasar pájaros, en la que también se observa una marcada preocupación por la experimentación, se aparta, no obstante, de la orientación mítica. El interés renovador se aprecia, sobre todo, en el juego de perspectivas incorporadas por la voz narrativa y en su repercusión en la estructura del relato. El narrador, que adopta la tercera persona, alterna entre la omnisciencia y una cierta equisciencia, limitación que incrementa la verosimilitud del relato y el acercamiento a la psicología de los diversos personajes. Este acercamiento, sin embargo, no agota las necesidades informativas del lector, lo que determina su implicación en la interpretación de los acontecimientos. Se aleja, por tanto, del realismo testimonial de la primera novela, por un notable incremento del subrayado lírico, el contrapunto burlesco y las intervenciones del narrador comentarista. Se aparta, también, de los toques míticos presentes en Ágata ojo de gato, adoptando a este respecto una limitación temporal más evidente.

Este funcionamiento del narrador se ajusta a lo propio del relato novelístico. También el planteamiento ficcional responde a las características del género, a pesar de la presencia de numerosos elementos personales. Entre estos rasgos puede señalarse la per- 
cepción sensorial del entorno, tramitada a través de una profusa construcción retórica. También el narrador refleja un rasgo señalado de autor implícito: una mirada crítica con frecuentes notas animalizadoras, abundantes cosificaciones y numerosos comentarios irónicos sobre los personajes, valoraciones que alcanzan también a algunos aspectos de la sociedad española.

En definitiva, todos los factores analizados resultan representativos de una obra de ficción basada en la experiencia personal del escritor y en la historia de su tierra a lo largo de buena parte del siglo XX. Se aprecia en ella un afianzamiento de las conexiones con otros relatos, aspecto que refuerza en el lector la impresión de hallarse en un mundo literario sólido, cimentado en la realidad concreta de la Andalucía atlántica.

La cuarta novela, En la casa del padre, juega con la alternancia entre dos voces narrativas: un narrador intradiegético identificado con la figura de José Daniel, un joven descendiente de don Sebastián Romero-Bárcena perteneciente a una rama secundaria, y otro narrador de carácter extradiegético. El primero recoge el punto de vista de un joven en un proceso de construcción personal, motivo que encaja ciertamente con uno de los tópicos principales de la autobiografía. En esta figura se pueden reconocer, asimismo, algunos rasgos que remiten al autor implícito, como la progresiva toma de conciencia, la confusión sentimental, la visión crítica de la realidad... El narrador omnisciente, en cambio, se sirve de una tercera persona externa al relato para referir aspectos previos a la intervención de José Daniel. Se establece así un juego de contrapunto que constituye uno de los atractivos del relato. Con todo, no está justificada textualmente la identificación de José Daniel con el autor, de modo que no se cumple uno de los requisitos tradicionales de la escritura autobiográfica. La intervención del otro narrador acaba poniendo de relieve el carácter ficcional del relato.

En definitiva, se trata de una historia que combina dos modelos narrativos complementarios: la saga familiar realista y el relato de formación, dos líneas en las que abundan, como se ha señalado, la manipulación de la experiencia autobiográfica y su integración en la materia narrativa.

Campo de Agramante, la quinta novela de Caballero Bonald, supone un cambio notable de planteamiento respecto a las obras anteriores, si bien permanecen algunos aspectos comunes a la obra narrativa del escritor. El narrador protagonista, un joven afectado por ciertos trastornos psicológicos, escribe una especie de dietario como medio de preservar su memoria. Se trata de una redacción discontinua, en la que se observa la evolución de la enfermedad padecida por el personaje, y su progresiva toma de conciencia de la situación.

Campo de Agramante se presenta, pues, como una novela de formación centrada en un proceso de búsqueda personal, cuyo objetivo básico es el autoconocimiento y la superación de los trastornos del protagonista. A este respecto, el relato supone un viraje notable respecto a la narrativa precedente del autor: frente a la dimensión sociohistórica, que tanto relieve alcanza con En la casa del padre, prevalece el interés por la intimidad.

No obstante, este relato no responde al modelo autobiográfico si nos atenemos a las exigencias formales: no hay identidad entre autor, narrador y personaje, el texto no persigue una reconstrucción global de la experiencia personal y no se ajusta a una perspectiva fija como referencia única. Tiene, a este respecto, cierta relación con la escritura diarística, si bien el narrador no precisa las indicaciones temporales ni mantiene una 
continuidad en la escritura. En realidad, el relato se ciñe al modelo de la novela de ficción, en cuanto que no se postula la identidad de las instancias narrativas, ni se establece un pacto de veredicción. Todo ello a pesar de las evidentes conexiones con la biografía del autor: en particular, las anomalías sensoriales padecidas como resultado de una isquemia cerebral.

Tiempo de guerras perdidas es la primera entrega de las dos novelas de la memoria. Este subtítulo destaca, precisamente, un punto de partida ambiguo que el texto no acaba de resolver. En cuanto al narrador, se trata de una voz en primera persona que se identifica con el autor y a la vez funciona como protagonista de la historia. Asimismo, esta instancia narrativa, desde el presente de la enunciación, recupera el pasado con la intención de explicarlo y así explicarse. Ahora bien, la creciente importancia del entorno, conforme avanza la historia, hace pensar en la proximidad del relato respecto de la escritura memorialística, lo que se aprecia en una mirada más amplia, que desborda el interés por la figura central incorporando numerosos personajes secundarios. De esta manera, el lector percibe la construcción de todo un paisaje humano, que alterna con la trama central, focalizada en torno al proceso de formación del protagonista.

En este relato, destacan algunos rasgos del narrador que ponen en duda su fiabilidad. Se trata de un punto de gran interés que conecta con el cuestionamiento genérico de la autobiografía planteado, entre otros, por Paul de Man (1979) o Paul J. Eakin (1985).Así, el protagonista reconoce la dificultad para la recuperación efectiva de la memoria. Se conforma con reflejar en la escritura no ya lo sucedido, sino el sedimento dejado por la experiencia al albur de la arbitrariedad de la memoria. Por otro lado, el propio proceso de la escritura introduce, en opinión del narrador, otro factor de distorsión, hasta el punto de que, desde su perspectiva, la validez del relato reside no tanto en la exactitud del recuerdo, sino en su eficacia literaria. De ahí el reconocimiento del papel de la evocación como mecanismo creativo: los olvidos, voluntarios o no, desencadenan un proceso de cierta conexión con la escritura ficcional.

En definitiva, las referencias autobiográficas son evidentes: es notoria la identificación entre el autor, el narrador y el protagonista, así como la importancia del proceso de formación del personaje, percibido desde el presente de la enunciación. Ahora bien, todos estos materiales autobiográficos, en ocasiones derivados hacia la escritura memorialística, se convierten en sustancia literaria, desencadenando ciertos resortes propios de la ficción. Así, el texto relativiza el pacto de verosimilitud, hasta el punto de plantearse como una novela, género básicamente ficcional. Esta ruptura de la distinción entre escritura autobiográfica y novelística supone un contrato de lectura ambiguo, cuyo único compromiso es la consideración literaria de la escritura como norma principal.

La ambigüedad de Tiempo de guerras perdidas se afianza en La costumbre de vivir. Se observa en esta última narración una mezcla de los códigos autobiográfico, memorialístico y novelístico, lo que constituye un proceso acorde, por otro lado, con la tendencia contemporánea a la indistinción genérica, que Jacques Lecarme y Elaine Lecarme-Tabone comentan en su estudio sobre la autobiografía (1997). Como indican las investigaciones más solventes sobre la autobiografía en España (Caballé, 1995; Romera Castillo, 2006), la renovación del género pasa a menudo por la invalidación de sus fronteras.

Así, llama la atención, en la abundante reflexión metaliteraria que contienen estas novelas de la memoria, la insistencia en el problema del autoconocimiento. El narrador su- 
braya la dificultad para juzgar la validez del recuerdo, particularmente aquel que resulta conflictivo. Asimismo, destaca su convencimiento acerca del carácter engañoso de la identidad y de la verdad. A este respecto, por su dimensión verbal, la voz narrativa pone de relieve la vertiente creativa de toda escritura, incluso la autobiográfica. Se trata de una percepción compartida por la crítica contemporánea, que desde perspectivas no siempre coincidentes subraya la dimensión poiética de la escritura (Villanueva, 1991).

En este contexto teórico, la presentación de una autobiografía como «novela de la memoria» subraya precisamente este carácter creativo, liberado de las ataduras inherentes al pacto autobiográfico, en particular la exigencia de identidad y de veracidad. La insistencia del autor en la escasa fiabilidad de su evocación, que se refleja en la reconstitución del pasado, se relaciona con la prevalencia de lo literario como criterio principal, según el pacto narrativo planteado en el relato. De ahí la identificación entre autobiografía y novela.

En efecto, sobre la base más ortodoxa del relato autobiográfico, cimentada en la recuperación retrospectiva del proceso de formación personal desde el presente de la enunciación, el autor construye una narración que parece empeñada en desmontar los presupuestos básicos de la autobiografía. Por un lado, la identidad se diluye en tanto que el protagonista funciona como un personaje en quien el narrador casi ya no se reconoce. Por otra parte, la veracidad de la historia entra en crisis en la medida en que el narrador subraya el carácter hipotético de algunas evocaciones y asegura la prevalencia del enfoque literario sobre cualquier otro. Todo lo cual configura una propuesta literaria de primer orden cimentada en un «estilo» muy personal (Pozuelo Yvancos, 2006).

En definitiva, la elección del subtítulo «novela de la memoria» marca con claridad meridiana la apuesta literaria del autor, que combina según su conveniencia los pactos novelístico, memorialístico y autobiográfico. De este modo, la obra narrativa del autor jerezano revela, a este respecto, su contemporaneidad, tanto por lo que se refiere a la importancia del material personal como a la diversidad de pactos narrativos y su ambigüedad final.

Así como la presencia del material autobiográfico es evidente en las obras de ficción, el componente ficcional es también inseparable de la escritura memorialística, tal como la interpreta el escritor jerezano. Son numerosísimas las reflexiones metaliterarias en que el autor-narrador-protagonista de Tiempo de guerras perdidas y La costumbre de vivir subraya la deriva ficcional de su discurso, relacionada con el mecanismo de la escritura y con la propia dinámica del recuerdo. Abundan también las declaraciones en que el escritor defiende la prioridad literaria de su tarea narrativa, por encima de fidelidades biográficas o históricas, como señala en un artículo aparecido con el significativo título de «Autobiografía y ficción» (1999: 365-366).

En conclusión, de este análisis se desprende la importancia de la experiencia personal en la configuración de la obra narrativa del escritor jerezano; la heterogeneidad de los contratos de lectura, que oscilan de la ficcionalidad al memorialismo; y, especialmente, la prevalencia del criterio literario en la construcción del universo narrativo del autor. Todo lo cual constituye una evidencia de la destacada contribución de José Manuel Caballero Bonald a la renovación de los géneros novelístico y autobiográfico. 


\section{BIBLIOGRAFIA}

CABALlÉ, Anna (1995): Narcisos de tinta. Ensayos sobre la literatura autobiográfica en lengua castellana (siglos XIX y XX), Málaga, Magazul.

CABALLERo Bonald, José Manuel (1999): Copias del natural, Madrid, Alfaguara.

DE MAN, Paul (1979): «La autobiografía como des-figuración», VV.AA. (1991): La autobiografía y sus problemas teóricos. Estudios e investigación documental, Barcelona, Suplementos Anthropos 29, pp. 113-118.

EAKIN, Paul J. (1985): «Autoinvención en la autobiografía: el momento del lenguaje», en VV.AA. (1991): La autobiografía y sus problemas teóricos. Estudios e investigación documental, Barcelona, Suplementos Anthropos 29, pp. 79-93.

LeCARME, Jacques y Elaine LeCARME-TABone (1997): L'autobiographie, Paris, Armand Colin.

LEJEUne, Philippe (1994): El pacto autobiográfico y otros estudios, Madrid, Megazul-Endymión.

Pozuelo Yvancos, José María (2006): De la autobiografía. Teoría y estilos, Barcelona, Crítica.

Romera CastiLlo, José (2006): De primera mano. Sobre escritura autobiográfica en España (siglo XX), Madrid, Visor.

VillanueVa, Darío (1991): «Para una pragmática de la autobiografía», Polen de ideas, Barcelona, PPU, pp. 95-114. 